\title{
Tailored covalently cross-linked hydrogels based on oxidized cellulose sulfate and carboxymethyl chitosan by targeted adjustment of the storage modulus
}

\author{
Juliane Strätz (D) Steffen Fischer
}

Received: 31 January 2020/Accepted: 3 June 2020/Published online: 20 June 2020

(C) The Author(s) 2020

\begin{abstract}
In general hydrogel synthesis uses a trial and error method when creating new hydrogels and searches afterwards for a fitting application of the received hydrogel. A much more effective and sustainable approach would be to have an application in mind before starting a targeted synthesis of a hydrogel with specific properties. Hence the goal of the study is to investigate influencing factors-crosslink density here represented through the degree of substitution, mass average molecular mass, mixing ratio and time for gelation- to the storage modulus $G^{\prime}$ for covalently cross-linked hydrogels based on oxidized cellulose sulfate and carboxymethyl chitosan. The results can be summarized as follows: higher values for $G^{\prime}$ can be reached by increasing the mass average molecular mass, the crosslink density and by shifting the mixing ratio toward the polymer which determines the number of possible cross-linkings in the hydrogel. The findings of this work may be transferred to similar systems and are helpful for a targeted synthesis of hydrogels with specific characteristics.
\end{abstract}

J. Strätz $(\bowtie) \cdot$ S. Fischer

Institute of Plant and Wood Chemistry, Technische

Universität Dresden, Pienner Str. 19, 01737 Tharandt,

Germany

e-mail: juliane.straetz@tu-dresden.de
Keywords Hydrogel $\cdot$ Rheology $\cdot$ Oxidized cellulose sulfate $\cdot$ Carboxymethyl chitosan $\cdot$ Storage modulus

\section{Introduction}

In times of scarcer fossil raw resources and climate change the demand for sustainable materials increases drastically (Clark et al. 2009; Joseph and TretsiakovaMcNally 2010; Iwata 2015). Even in the field of hydrogels alternatives to fossil based products are favored and research is conducted (Simões et al. 2019). Therefore biopolymers become very attractive because they are widely available, renewable and biodegradable (Bashari et al. 2018; Maleki et al. 2016).

Cellulose and chitosan are one of the most abundant natural polymers (Abe and Higashi 1991; Lalani and Misra 2011) and so a great alternative as a parent substance for hydrogel synthesis.

Cellulose is the main component in plant cell walls. It consists of cellobiose monomers, which are connected through $\beta$ - $(1 \rightarrow 4)$-glycosidic bonds to form a unbranched polymer chain that is insoluble in water. Chemical reactions happen mainly at the three hydroxyl groups of the anhydroglucose unit (AGU) where various functional groups can interact and change the properties of the cellulose. An example of 
this is the introduction of sulfate groups which even leads to a water soluble cellulose derivative (Wagenknecht et al. 1992).

Chitosan is the most important chitin derivate and is obtained under alkaline conditions by partial deacetylation of chitin (Chandy and Sharma 1990). It is constructed by $\beta$-(1 $\rightarrow 4)$-glycosidic linked D-glucosamines and $\mathrm{N}$-acetyl-D-glucosamines, furthermore it is unbranched like cellulose. From a degree of deacetylation (DD) $D D$ above $50 \%$ chitin becomes water soluble under acidic conditions and is called chitosan (Rinaudo 2006). Whereas cellulose has a plant based origin, most chitin and consequently chitosan is originated from crustaceans such as shrimp and crabs, where it is the structural element in the exoskeleton (Puvvada et al. 2012).

Using the example of cellulose and chitin one can see that derivatization leads to products with new properties. These properties define later possible applications. Generally, hydrogels can be found in all areas of life from wastewater treatment, where selected ions or bacteria are removed from the water (Mehrotra et al. 2020; Chauhan et al. 2007), over soil amendment to increase water retention and improve plant growth under drying climate stress (Mathes et al. 2020; Senna et al. 2015) up to tissue engineering (Daniele et al. 2014; Alsberg et al. 2001) and drug release (Juriga et al. 2019; Ashley et al. 2013).

In order to be able to synthesize hydrogels specifically for certain applications, and not the other way around to find an application for a specific hydrogel, influencing factors have to be well known. Influencing factors are not restricted to functional groups, they also include among others the degree of substitution $(D S)$ and molecular weight of the polymer, the type of hydrogel (chemical or physical cross-linked) as well as the type of the formed network (Burdick and Murphy 2012; Ahmed 2015).

For that reason the aim of the study is to investigate potential influencing factors to the storage modulus $G^{\prime}$ for covalent cross-linked hydrogels consisting of oxidized cellulose sulfate (oCS) and carboxymethyl chitosan $(\mathrm{CMCh})$. Here the impact of $D S$, mass average molecular mass $\left(M_{\mathrm{w}}\right)$, mixing ratio and time for gelation on the storage modulus is studied.

\section{Experimental}

Chemicals and reagents

Sulfite pulp $\left(D P_{\mathrm{W}}=1300\right)$ was received from Lenzing (Lenzing, Austria), cotten linters $\left(D P_{\mathrm{W}}=6000\right)$ was received from Milouban (Ashrat, Israel). Carboxymethyl chitosan $(D S=1, \quad D D=94.2 \%$, $M_{\mathrm{w}}=83.2 \mathrm{kDa}$ ) was purchased from Heppe Medical Chitosan GmbH (Halle (Saale), Germany). Ethanol 99.5\% denatured was purchased from Grüssing (Filsum, Germany), chlorosulfuric acid for synthesis and $\mathrm{KH}_{2} \mathrm{PO}_{4}$ p.a. from Merck (Darmstadt, Germany), hydroxylammonium chloride technical was purchased from VWR (Darmstadt, Germany). Dimethylformamide (DMF) 99\% and sodium periodate $\geq 99.0 \%$ were purchased from Sigma Aldrich (Munich, Germany), ethylene glycol $\geq 99.5 \%$ p.a., glacial acetic acid, potassium chloride $\geq 99 \%, \quad \mathrm{Na}_{2} \mathrm{HPO}_{4}$. $2 \mathrm{H}_{2} \mathrm{O} \geq 99.5 \%$ p. a., sodium chloride $\geq 99.9 \%$ CELLPURE $^{\circledR}$, sodium hydroxide and sodium acetate trihydrate were obtained from Carl Roth (Karlsruhe, Germany). DMF was dried over molecular sieve with a pore size of $3 \AA$. All other reagents were used without further purification. All aqueous solutions were prepared using deionized water. Dialysis membranes from Spectra/Por ${ }^{\circledR}$ had a molecular weight cut off of $100 \mathrm{Da}$ to $500 \mathrm{Da}$ and of $3.5 \mathrm{kDa}$.

Sulfation and oxidation were conducted like described before (Strätz et al. 2019).

\section{Sulfation of cellulose}

For both variations of sulfation pretreatment was the following: Cellulose (2.50 g; $0.0154 \mathrm{~mol})$ was soaked in $125 \mathrm{ml} \mathrm{DMF}$ at ambient temperature for $24 \mathrm{~h}$. Dialysis was carried out using a standard regenerated cellulose membrane with a molecular weight cut off of $3.5 \mathrm{kDa}$.

Direct sulfation The reaction agent consisting of DMF (25 ml) and chlorosulfuric acid (0.0462 mol, 3.0 eq.; 0.0693 mol, 4.5 eq.; $0.0924 \mathrm{~mol}, 6.0$ eq.) was prepared while cooling in an ice bath. The sulfating agent was added dropwise to the soaked cellulose at room temperature (RT). After $3 \mathrm{~h}$ of vigorous stirring the now clear solution was poured in an ethanolic solution $(500 \mathrm{ml})$, which contained $\mathrm{NaOH}$ (14.3 g, $0.358 \mathrm{~mol}), \mathrm{NaOAc} \cdot 3 \mathrm{H}_{2} \mathrm{O}(11.05 \mathrm{~g}, 0.0812 \mathrm{~mol})$ and 
$\mathrm{H}_{2} \mathrm{O}(26.5 \mathrm{ml})$ filled up to $500 \mathrm{ml}$ with ethanol (99\%). The precipitate had to rest at least $12 \mathrm{~h}$ before the supernatant was removed by centrifugation. Afterwards the sediment was washed two times with $4 \%$ ethanolic/aqueous (v:v; 1:1) sodium acetate solution $(100 \mathrm{ml})$. The product was dissolved in a minimum of $\mathrm{H}_{2} \mathrm{O}$ and the $\mathrm{pH}$ was adjusted to 8.0 with glacial acetic acid. Next, the cellulose sulfate was precipitated and dissolved two more times, then dialyzed and lyophilized.

Acetosulfation The reaction agent consisting of $\operatorname{DMF}(25 \mathrm{ml})$, chlorosulfuric acid $(0.0462 \mathrm{~mol}, 3.0$ eq.) and acetic anhydride ( $0.123 \mathrm{~mol}, 8.0$ eq.) was prepared while cooling in an ice bath. The sulfating agent was added dropwise to the soaked cellulose and heated to $50{ }^{\circ} \mathrm{C}$, followed by $5 \mathrm{~h}$ of intense stirring at $50{ }^{\circ} \mathrm{C}$. To quench the reaction the solution was poured in an ethanolic solution $(500 \mathrm{ml})$ which contained $\mathrm{NaOH}$ (14.3 g, $0.358 \mathrm{~mol}), \mathrm{NaOAc} \cdot 3 \mathrm{H}_{2} \mathrm{O}$ (11.05 g, 0.0812 mol) and $\mathrm{H}_{2} \mathrm{O}(26.5 \mathrm{ml})$ filled up to $500 \mathrm{ml}$ with ethanol (99\%). The precipitate had to rest at least $12 \mathrm{~h}$ before the supernatant was removed by centrifugation. The sediment was washed two times with $4 \%$ ethanolic/aqueous (v:v; 1:1) sodium acetate solution (100 $\mathrm{ml})$. The product was then dissolved and stirred for 20 $h$ at ambient temperature in $\mathrm{NaOH}(50 \mathrm{ml}, 1 \mathrm{~mol} / \mathrm{l})$ for deacetylation, thereafter the $\mathrm{pH}$ was adjusted to 8.0 using glacial acetic acid. The (CS) was precipitated and dissolved two more times, then dialyzed and lyophilized.

\section{Oxidation of cellulose sulfate}

CS (1.5 g) was dissolved in water $(60 \mathrm{ml})$ and sodium periodate ( $1.5 \mathrm{~g}$; $0.007 \mathrm{~mol}$; 1 weight equivalent) was added. The solution was stirred at ambient temperature under exclusion of light for $6 \mathrm{~h}$. By adding ethylene glycol ( $1.5 \mathrm{ml} ; 0.027 \mathrm{~mol})$ and stirring for another hour the reaction was quenched. The oCS was precipitated in ethanol (300 ml), dialyzed using a cellulose ester membrane with a molecular weight cut off of $100 \mathrm{Da}$ to $500 \mathrm{Da}$ and lyophilized to obtain a white solid product.

\section{Cross-linking of oCS and CMCh}

All gels had the same total concentration of 0.09 $\mathrm{mmol} / \mathrm{ml}$. Four different mixing ratios for oCS:CMCh $(1: 1 ; 1: 3 ; 1: 5 ; 1: 10)$ were prepared. The ratio was calculated for the amount of substance of the aldehyd of the oCS and the corresponding amount of required CMCh.

oCS and $\mathrm{CMCh}$ were each dissolved in $100 \mu \mathrm{l}$ phosphate-buffered saline (PBS) $(\mathrm{KCl}(0.2 \mathrm{~g}), \mathrm{NaCl}$ $(8.0 \mathrm{~g}), \mathrm{KH}_{2} \mathrm{PO}_{4}(0.19 \mathrm{~g})$ and $\mathrm{Na}_{2} \mathrm{HPO}_{4} \cdot 2 \mathrm{H}_{2} \mathrm{O}(0.765$ g) filled up to 11 with deionized water, afterwards the $\mathrm{pH}$ was adjusted with $\mathrm{NaOH}$ to 7.4). Then both solutions were mixed together $1: 1(v: v)$ in a vial and stirred at ambient temperature with a stirring rod until a colorless gel was obtained. The time until the colorless gel was formed is referred to as gelation time. The formed hydrogels rested for $24 \mathrm{~h}$ before they were overlaid with PBS $(3 \mathrm{ml})$ for $24 \mathrm{~h}$ until the rheologic measurement.

\section{Microwave digestion and ICP-OES}

Dry CS $(0,01 \mathrm{~g})$ was mixed with hydrogen peroxide (2 $\mathrm{ml} ; 30 \%)$ and nitric acid ( $3 \mathrm{ml} ; 65 \%)$. The microwave digestion was run with a Mars microwave by CEM (Kamp-Lintfort, Germany) using a two-step program. Step one: $1600 \mathrm{~W}, 100 \%$ power, temperature ramp 10 min, $\vartheta=100^{\circ} \mathrm{C}$, keep temperature for $5 \mathrm{~min}$. Step two: $1600 \mathrm{~W}, 100 \%$ power, temperature ramp $10 \mathrm{~min}$, $\vartheta=180^{\circ} \mathrm{C}$, keep temperature for $15 \mathrm{~min}$.

The sulfur content was measured using the emission spectrometer Ciros CCD by Spectro (Kleve, Germany) with a plasma power of $1400 \mathrm{~W}$ and argon gas. The $D S$ was calculated with Eq. 1 based on the determined sulfur content.

$$
D S_{\text {Sulf }}=\frac{162.1 \cdot S(\%)}{3207-102.1 \cdot S(\%)}
$$

Determination of aldehyde content

A blank consisting of hydroxylammonium chloride $(0.4 \mathrm{~mol} / \mathrm{l} ; 20 \mathrm{ml})$ and deionized water $(25 \mathrm{ml})$ was made and the $\mathrm{pH}$ was measured. Dialyzed oCS (60.0 $\mathrm{mg}$ ) was dissolved in deionized water $(25 \mathrm{ml})$ and the $\mathrm{pH}$ was adjusted to 7.0 using sodium hydroxide $(0.01$ $\mathrm{mol} / \mathrm{l})$. After adding hydroxylammonium chloride ( 0.4 $\mathrm{mol} / \mathrm{l} ; 20 \mathrm{ml})$, the reaction mixture was stirred for a minimum of three hours at $\mathrm{RT}$. The released $\mathrm{HCl}$ was titrated with $\mathrm{NaOH}(0.01 \mathrm{~mol} / \mathrm{l})$ until the $\mathrm{pH}$ of the blank was reached. The amount of aldehyde given as $D S_{\text {Ald }}$ was calculated by the following equation: 


$$
D S_{\mathrm{Ald}}=\frac{6 \cdot M_{\mathrm{C}} \cdot 0.01 \cdot t_{\mathrm{NaOH}} \cdot V_{\mathrm{NaOH}}}{C(\%) \cdot m}
$$

$M_{\mathrm{C}}$ molar masse of carbon atom $(12.01 \mathrm{~g} / \mathrm{mol}), t_{\mathrm{NaOH}}$ titer of $0.01 \mathrm{~mol} / 1 \mathrm{NaOH}, V_{\mathrm{NaOH}}$ volume of consumed $0.01 \mathrm{~mole} / \mathrm{l} \mathrm{NaOH}$ solution in $\mathrm{ml}, m$ : mass of sample in $\mathrm{mg}, C(\%)$ carbon content of sample in \%, the carbon content was calculated taking account of $D S_{\text {Sulf }}$ instead of measuring the carbon content by elemental analysis.

\section{Measurements}

Size-exclusion chromatography (SEC) was performed on a Azura (Knauer, Germany) equipped with UV detector (UVD-2.1S) under following conditions: columns: Suprema precolumn, Suprema 1000, Suprema 30; column temperature: $30.00^{\circ} \mathrm{C}$; eluent: 0.1 mole/ $/ \mathrm{NaNO}_{3} / 0.05 \% \mathrm{NaN}_{3}$; flowrate: $1.000 \mathrm{ml} /$ min; standards: pullulan. All samples were filtered through a syringe filter (cellulose acetate, pore size $0.45 \mu \mathrm{m}$ ) ahead the injection.

The frequency sweep was conducted using an AresG2 (TA Instruments) under following conditions: 15 $\mathrm{mm}$ parallel plate; temperature: $25^{\circ} \mathrm{C}$; strain: $3.0 \cdot 10^{-3}$; logarithmic sweep; angular frequency: 0.1 $\mathrm{rad} / \mathrm{s}$ to $100 \mathrm{rad} / \mathrm{s}$.

SEM images were taken with an ESEM Quanta 650 FEG (FEI). Samples were lyophilized and then sputtered with gold using an ion sputter JFC 1100E (Jeol, Germany).

\section{Results and discussion}

The properties of hydrogels and the tuning of these plays an important role when it comes to possible application areas. This study is focused on $G^{\prime}$ and whereby it is influenced. An overview of the investigated samples and their properties is shown in Table 1.

At the beginning four parameters were chosen: $D S_{\text {Ald }}, M_{\mathrm{w}}$, mixing ratio and time of gel formation. The $D S_{\text {Ald }}$ determines the number of possible cross-links since the number of amine groups in $\mathrm{CMCh}$ is much higher. $G^{\prime}$ should be influenced by the $M_{\mathrm{W}}$ due to the chain length and needs to be examined. Regarding the mixing ratio it is interesting to know if a higher ratio of CMCh leads to a lower $G^{\prime}$ because of many unreacted and/or minimal crosslinked chitosan molecules. Due to the fact that the differences in time for gel formation are considerable, a potential relation between time for gel formation and $G^{\prime}$ was evaluated.

To make sure that just the four chosen parameters effect $G^{\prime}$ all gels had the same total concentration of $0.09 \mathrm{mmol} / \mathrm{ml}$. Furthermore all hydrogels were swollen for $24 \mathrm{~h}$ to reach swelling equilibrium to have a defined state of swelling to compare the properties of the gels. Because without $24 \mathrm{~h}$ of swelling the gels would have different states of swelling depending on the number of possible cross-links for each sample.

As shown in Fig. 1 highest values for $G^{\prime}$ were reached by oCS with highest $D S_{\text {Ald }}$ independent of the mixing ratio. The result matches the expectation that a higher amount of cross-links leads to higher values of $G^{\prime}$. A highly crosslinked hydrogel cannot swell as much as a low crosslinked one, for this reason highly crosslinked hydrogels are stiffer and reach higher $G^{\prime}$ (Schacht et al. 1997). In Fig. 2 are SEM images of freeze-dried hydrogels of the samples 1 and 3 with a $D S_{\text {Ald }}$ of 0.34 and 0.09 presented to illustrate the differences in swelling and to understand the variation in their $G^{\prime}$. When looking at Fig. 2c and comparing with Fig. 2d the low crosslinked sample 3 features a lot more cavities than the higher crosslinked sample 1 .
Table 1 Overview of the investigated samples, their sulfation method, molar equivalents of sulfating agent $\mathrm{HSO}_{3} \mathrm{Cl}$ and properties

\begin{tabular}{lllllll}
\hline Source & Sample & Method & Eq. $\mathrm{HSO}_{3} \mathrm{Cl}$ & $D S_{\text {Sulf }}$ & $D S_{\text {Ald }}$ & $M_{\mathrm{w}}[\mathrm{Da}]$ \\
\hline Sulfite pulp & 1 & Aceto & 3.0 & 0.82 & 0.34 & 74,300 \\
& 2 & Direct & 3.0 & 1.27 & 0.10 & 43,700 \\
& 3 & Direct & 6.0 & 2.04 & 0.09 & 50,900 \\
Cotton linters & 4 & Aceto & 3.0 & 0.75 & 0.33 & 82,000 \\
& 5 & Direct & 3.0 & 1.30 & 0.11 & 34,300 \\
& 6 & Direct & 4.5 & 1.50 & 0.07 & 47,100 \\
& 7 & Direct & 6.0 & 1.61 & 0.03 & 26,800 \\
\hline
\end{tabular}




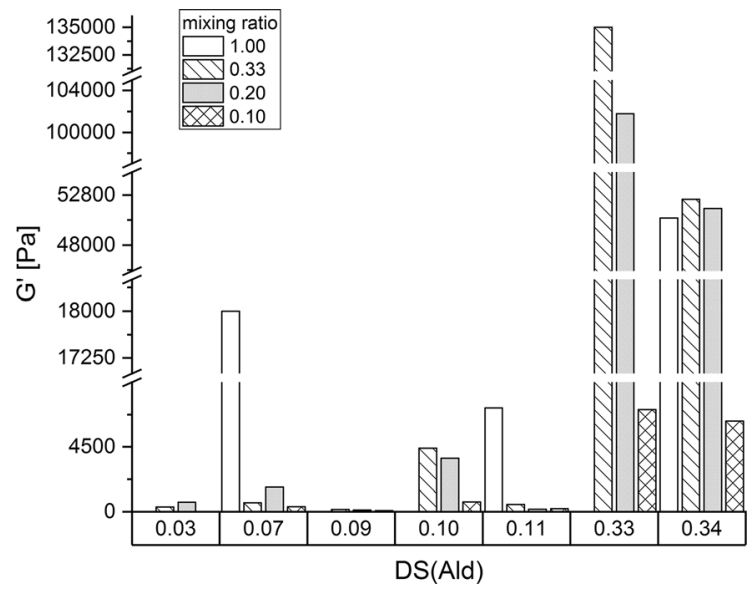

Fig. $1 G^{\prime}$ depending on $D S_{\text {Ald }}$ and mixing ratio of oCS:CMCh

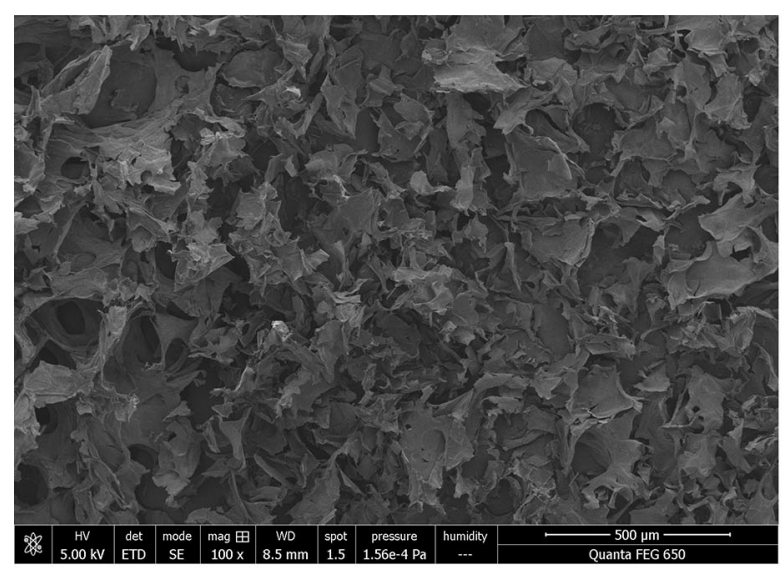

(a) sample 1 with 100x magnification

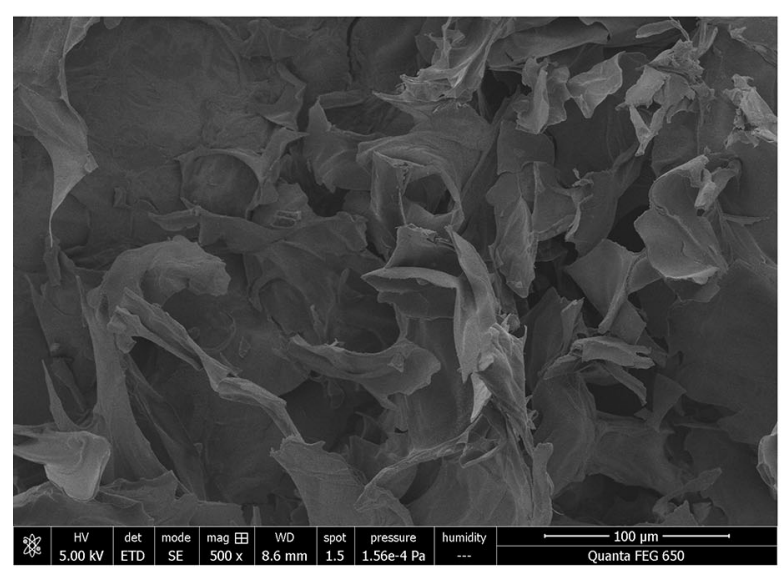

(c) sample 1 with $500 \mathrm{x}$ magnification
While the amount of possible cross-links is at least three times as much for the samples with $D S_{\text {Ald }}=0.33$ and $D S_{\text {Ald }}=0.34$ in comparison to the other, the variation in $G^{\prime}$ is broadly distributed. This observation might have its cause in one of the other studied parameters.

When looking at Fig. 3 one can see that with increasing $M_{\mathrm{w}} G^{\prime}$ increases as well. The influence of $M_{\mathrm{w}}$ on $G^{\prime}$ outweighs the influence of the $D S_{\text {Ald }}$ as you see when comparing the samples with the $D S_{\text {Ald }}=$ 0.33 and $D S_{\text {Ald }}=0.34$. Although the samples with the highest $M_{\mathrm{w}}$ also have the highest $D S_{\mathrm{Ald}}$ the same effect can be noticed for the samples with $D S_{\text {Ald }}=0.10$ and $D S_{\text {Ald }}=0.11$.

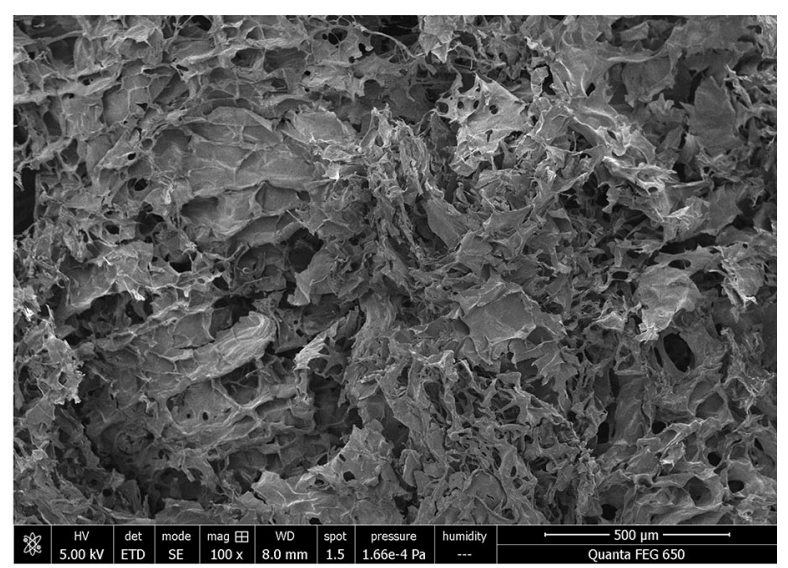

(b) sample 3 with $100 x$ magnification

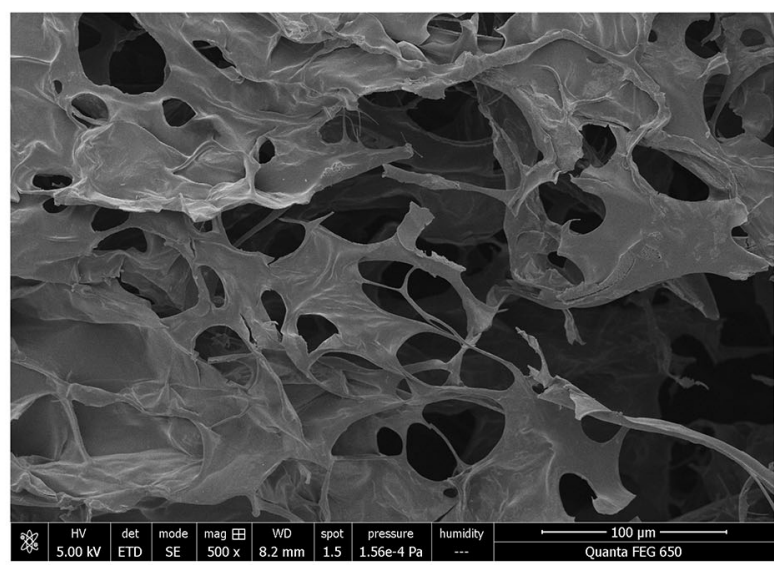

(d) sample 3 with 500x magnification

Fig. 2 SEM images of the samples $1\left(D S_{\text {Ald }}=0.34\right)$ and $3\left(D S_{\text {Ald }}=0.09\right)$ with 2 different magnifications. Both samples were prepared as described before with a mixing ratio of 1:1 and deionized water instead of PBS, after $24 \mathrm{~h}$ of swelling the hydrogels were lyophilized 


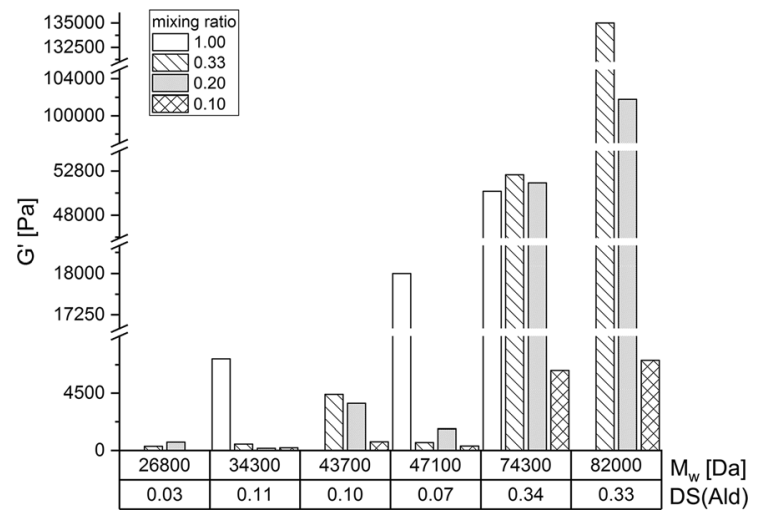

Fig. $3 G^{\prime}$ depending on $M_{\mathrm{w}}$ and mixing ration of oCS:CMCh, for comparison $D S_{\text {Ald }}$ is also shown

Additionally to the covalent bonds between oCS and $\mathrm{CMCh}$ polymer entanglement might also contribute to the gel formation and the stiffness of the resulting hydrogel (Tsukeshiba et al. 2005). Longer polymer chains have more possibilities of entanglement than shorter ones which is another reason why the $M_{\mathrm{w}}$ influences $G^{\prime}$.

Another factor that should be considered is the time needed for gel formation. The here shown hydrogels can be categorized in three groups: (1) less than $1 \mathrm{~min}$ of gel formation, (2) $6 \mathrm{~h}$ to $12 \mathrm{~h}$ of gel formation and (3) $24 \mathrm{~h}$ of gel formation. The samples with shortest gelation time show the highest values for $G^{\prime}$ (Fig. 4) independent of the mixing ratio. Moreover the gelation time correlates with $D S_{\text {Ald }}$, with increasing gelation time the $D S_{\text {Ald }}$ decreases. An explanation for this is that with increasing $D S_{\text {Ald }}$ the number of possible

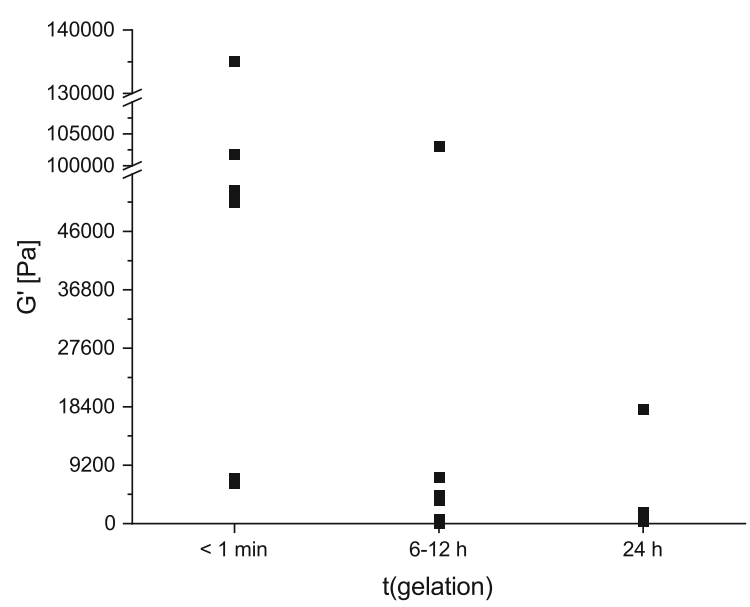

Fig. $4 G^{\prime}$ depending on time for gelation cross-links increase and thus a faster formation of covalent bonds is possible which results in a shorter gelation time. The relation between $D S_{\text {Ald }}$ and $G^{\prime}$ was discussed earlier.

Regarding the mixing ratio the expectation, that a higher amount of $\mathrm{CMCh}$ leads to lower $G^{\prime}$, was approved independent of other factors here $D S_{\text {Ald }}$ and $M_{\mathrm{w}}$ (Figs. 1 and 3 ). To reach as high as possible values for $G^{\prime}$ the mixing ratio should be shifted toward the polymer which determines the number of possible cross-linkings in the hydrogel to minimize the number of unreacted molecules. The variety of mixing ratios was strongly limited due to the solubility of oCS and $\mathrm{CMCh}$. But it was found that for a better miscibility of the two components their volumes should be equal. Otherwise instead of a colorless hydrogel a white sediment was received.

\section{Conclusion}

It could be shown that for hydrogels consisting of oCS and CMCh $G^{\prime}$ is dependent on the crosslink density, which is represented by the $D S_{\text {Ald }}$. Higher values for $D S_{\text {Ald }}$ result in higher values for $G^{\prime}$, because the number of possible cross-linkings increases with rising $D S_{\text {Ald }}$. Furthermore the storage modulus increases also when the $M_{\mathrm{w}}$ of the used polymer is raised due to increasing polymer entanglement. Moreover the mixing ratio of the gel forming components should be shifted toward the polymer which determines the number of possible cross-linkings in the hydrogel when aiming for a high value of $G^{\prime}$.

The findings of this study are helpful for a targeted synthesis of hydrogels with specific properties and may be transferred to similar systems.

Acknowledgments Open Access funding provided by Projekt DEAL. We thank Harald Rohm and Norbert Raak for the possibility and support to do the rheological measurements and Björn Günther for taking the SEM images. This work was financially supported by Deutsche Forschungsgemeinschaft (grant number FI 755/10-1).

\section{Compliance with ethical standards}

Conflict of interest The authors declare that they have no conflict of interest.

Open Access This article is licensed under a Creative Commons Attribution 4.0 International License, which permits use, 
sharing, adaptation, distribution and reproduction in any medium or format, as long as you give appropriate credit to the original author(s) and the source, provide a link to the Creative Commons licence, and indicate if changes were made. The images or other third party material in this article are included in the article's Creative Commons licence, unless indicated otherwise in a credit line to the material. If material is not included in the article's Creative Commons licence and your intended use is not permitted by statutory regulation or exceeds the permitted use, you will need to obtain permission directly from the copyright holder. To view a copy of this licence, visit http://creativecommons.org/licenses/by/4.0/.

\section{References}

Abe T, Higashi M (1991) Cellulose centered perspective on terrestrial community structure. Oikos 60(1):127-133

Ahmed EM (2015) Hydrogel: preparation, characterization, and applications: a review. J Adv Res 6(2):105-121. https:// doi.org/10.1016/j.jare.2013.07.006

Alsberg E, Anderson K, Albeiruti A, Franceschi R, Mooney D (2001) Cell-interactive alginate hydrogels for bone tissue engineering. J Dent Res 80(11):2025-2029. https://doi.org/ $10.1177 / 00220345010800111501$

Ashley GW, Henise J, Reid R, Santi DV (2013) Hydrogel drug delivery system with predictable and tunable drug release and degradation rates. Proc Natl Acad Sci 110(6):2318-2323. https://doi.org/10.1073/pnas. 1215498110

Bashari A, Rouhani Shirvan A, Shakeri M (2018) Cellulosebased hydrogels for personal care products. Polym Adv Technol 29(12):2853-2867. https://doi.org/10.1002/pat. 4290

Burdick JA, Murphy WL (2012) Moving from static to dynamic complexity in hydrogel design. Nat Commun 3(1):1-8. https://doi.org/10.1038/ncomms2271

Chandy T, Sharma CP (1990) Chitosan-as a biomaterial. Biomater Artif Cells Artif Org 18(1):1-24. https://doi.org/10. 3109/10731199009117286

Chauhan GS, Chauhan K, Chauhan S, Kumar S, Kumari A (2007) Functionalization of pine needles by carboxymethylation and network formation for use as supports in the adsorption of Cr6+. Carbohydr Polym 70(4):415-421. https://doi.org/10.1016/j.carbpol.2007.04. 020

Clark JH, Deswarte FEI, Farmer TJ (2009) The integration of green chemistry into future biorefineries. Biofuels Bioprod Biorefining 3(1):72-90. https://doi.org/10.1002/bbb.119

Daniele MA, Adams AA, Naciri J, North SH, Ligler FS (2014) Interpenetrating networks based on gelatin methacrylamide and peg formed using concurrent thiol click chemistries for hydrogel tissue engineering scaffolds. Biomaterials 35(6):1845-1856. https://doi.org/10.1016/j. biomaterials.2013.11.009

Iwata T (2015) Biodegradable and bio-based polymers: future prospects of eco-friendly plastics. Angew Chem Int Ed 54(11):3210-3215. 201410770
Joseph P, Tretsiakova-McNally S (2010) Sustainable nonmetallic building materials. Sustainability 2(2):400-427. https://doi.org/10.3390/su2020400

Juriga D, Sipos E, Hegedüs O, Varga G, Zrínyi M, Nagy KS, Jedlovszky-Hajdú A (2019) Fully amino acid-based hydrogel as potential scaffold for cell culturing and drug delivery. Beilstein J Nanotechnol 10:2579-2593. https:// doi.org/10.3762/bjnano.10.249

Lalani J, Misra A (2011) 4-gene delivery using chemical methods. In: Misra A (ed) Challenges in delivery of therapeutic genomics and proteomics. Elsevier, London, pp 127-206. https://doi.org/10.1016/B978-0-12-384964-9. 00004-9

Maleki L, Edlund U, Albertsson AC (2016) Green semi-ipn hydrogels by direct utilization of crude wood hydrolysates. ACS Sustain Chem Eng 4(8):4370-4377. https://doi.org/ 10.1021/acssuschemeng.6b00938

Mathes F, Murugaraj P, Bougoure J, Pham VT, Truong VK, Seufert M, Wissemeier AH, Mainwaring DE, Murphy DV (2020) Engineering rhizobacterial community resilience with mannose nanofibril hydrogels towards maintaining grain production under drying climate stress. Soil Biol Biochem. https://doi.org/10.1016/j.soilbio.2020.107715

Mehrotra T, Zaman MN, Prasad BB, Shukla A, Aggarwal S, Singh R (2020) Rapid immobilization of viable bacillus pseudomycoides in polyvinyl alcohol/glutaraldehyde hydrogel for biological treatment of municipal wastewater. Environ Sci Pollut Res. https://doi.org/10.1007/s11356019-07296-z

Puvvada YS, Vankayalapati S, Sukhavasi S (2012) Extraction of chitin from chitosan from exoskeleton of shrimp for application in the pharmaceutical industry. Int Curr Pharm J 1(9):258-263. https://doi.org/10.3329/icpj.v1i9.11616

Rinaudo M (2006) Chitin and chitosan: properties and applications. Prog Polym Sci 31(7):603-632. https://doi.org/10. 1016/j.progpolymsci.2006.06.001

Schacht E, Bogdanov B, Bulcke AVD, Rooze ND (1997) Hydrogels prepared by crosslinking of gelatin with dextran dialdehyde. React Funct Polym 33(2):109-116. https://doi. org/10.1016/S1381-5148(97)00047-3

Senna AM, do Carmo JB, da Silva JMS, Botaro VR (2015) Synthesis, characterization and application of hydrogel derived from cellulose acetate as a substrate for slow-release npk fertilizer and water retention in soil. J Environ Chem Eng 3(2):996-1002. https://doi.org/10.1016/j.jece. 2015.03.008

Simões BM, Cagnin C, Yamashita F, Olivato JB, Garcia PS, de Oliveira SM, Grossmann MVE (2019) Citric acid as crosslinking agent in starch/xanthan gum hydrogels produced by extrusion and thermopressing. LWT. https://doi. org/10.1016/j.lwt.2019.108950

Strätz J, Liedmann A, Trutschel ML, Mäder K, Groth T, Fischer S (2019) Development of hydrogels based on oxidized cellulose sulfates and carboxymethyl chitosan. Cellulose 26(12):7371-7382

Tsukeshiba H, Huang M, Na YH, Kurokawa T, Kuwabara R, Tanaka Y, Furukawa H, Osada Y, Gong JP (2005) Effect of polymer entanglement on the toughening of double network hydrogels. J Phys Chem B 109(34):16304-16309. https://doi.org/10.1021/jp052419n 
Wagenknecht W, Nehls I, Stein A, Klemm D, Philipp B (1992) Synthesis and substituent distribution of na-cellulose sulphates via o-trimethylsilyl cellulose as intermediate. Acta Polym 43(5):266-269. https://doi.org/10.1002/actp.1992. 010430505
Publisher's Note Springer Nature remains neutral with regard to jurisdictional claims in published maps and institutional affiliations. 